\title{
A INSUSTENTABILIDADE URBANA NUM CONTEXTO DE MEDO DO CRIME: PERCEPÇÕES DOS ADOLESCENTES DA PERIFERIA DE BELÉM-PA
}

\section{Jane Farias Ferreira ${ }^{1}$ \\ Rosália do Socorro da Silva Corrêa ${ }^{2}$}

Resumo: A insustentabilidade urbana se opõe a ideia de um espaço urbano estruturado com base na garantia de direitos, relativos à vida na cidade, para as atuais e futuras gerações. Esta perspectiva não admite a presença do sentimento de medo do crime, o que eliminaria qualquer possibilidade de vida social saudável e bem estar dos moradores. Com base nesse ideal de sustentabilidade o artigo apresenta uma discussão sobre criminalidade e o medo na percepção de adolescentes, moradores da periferia de Belém$P A$, área onde a criminalidade se apresenta de forma mais intensa e provoca o sentimento de medo, ao mesmo tempo em que estimula diferentes estratégias preventivas.

Palavras-chave: Insustentabilidade urbana; Medo do crime; Percepção dos Adolescentes.

\footnotetext{
${ }^{1}$ Mestranda do Programa de Mestrando em Desenvolvimento Meio Ambiente Urbano/Universidade da Amazônia - UNAMA, Belém- PA, Brasil. E-mail: janeffarias@yahoo.com.br.

2 Professora Doutora da Universidade da Amazônia - UNAMA/Programa de Mestrando em Desenvolvimento Meio Ambiente Urbano, Belém- PA, Brasil. E-mail: rosallyaco@gmail.com.
} 